\title{
A ORIGEM DO CONCEITO DE MULTIPLICIDADE SEGUNDO GILLES DELEUZE
}

Hélio Rebello CARDOSO JÚNIOR ${ }^{1}$

- RESUMO: Paraque o conceito de multiplicidade se tornasse um elemento central em seu pensamento, Deleuze se lança a uma intensa pesquisa, procurando, tanto na teoria da física de Riemann quanto na filosofia de Bergson, o uso que estes autores fazem da multiplicidade. Justamente nesse esforço, pode-se observar não apenas a aliança que Deleuze estabelece com certos autores, mas o caráter peculiar da criação deleuzeana de conceitos. Com efeito, a renovação das noções de tempo e de espaço nas noções riemanniana e bergsoniana de multiplicidade perfaz a originalidade deste mesmo conceito em sua formulação deleuzeana, pois ele adquire aí um alcance ontológico.

- PALAVRAS-CHAVE: Multiplicidade; Deleuze; Bergson; Riemann.

\section{Pesquisas deleuzeanas visando ao conceito de multiplicidade}

\section{Conceito de multiplicidade e o problema do uno e do múltiplo}

A multiplicidade é apresentada como conceito no livro dedicado a Bergson de 1966. Aí, Deleuze procura definir tipos de multiplicidade, tendo em vista a teoria físico-matemática de Riemann e o tratamento filosófico que lhe confere Bergson. Trata-se, portanto, de uma aliança filosófica com Bergson, e outra, de feição interdisciplinar, com a ciência. Por outro lado, o nascimento do conceito de multiplicidade em sua relação com a física relativista e com a filosofia da duração de Bergson, nas quais fica em destaque sua acepção temporal, não esgota a teoria deleuzeana das multiplicidades. Sendo assim, para enterdermos por que a teoria deleuzeana das multiplicidades não fica restrita ao registro da filosofia de Bergson, nem ao da teoria físico-matemática de Riemann, é necessário averiguar quais as linhas de força que Deleuze recolhe dessas tentativas de definir o conceito de multiplicidade, e que, afinal, lhe fornecem um ponto de partida.

1 Departamento de História - Centro de Letras e Ciências Humanas - Universidade Estadual de Londrina - 86051 -970 - Londrina - PR. 
Segundo Deleuze, a primeira regra do método filosófico de Bergson seria a de fazer a prova do verdadeiro e do falso nos próprios problemas, antes de submeter à mesma prova as soluções desses problemas, assunto que trataremos um pouco adiante. Não se trata, absolutamente, de qualificar como verdadeiro o problema que oferece uma solução, e como falso o que não a oferece. Todo problema merece a solução que a sua posição proporciona. Assim, os problemas verdadeiros são aqueles que reconciliam a verdade e a criação em nível de sua formulação (1966, p.3). Mas, de que maneira a posição dos problemas atuaria sobre o conceito de multiplicidade?

Justamente, a definição do conceito de multiplicidade foi bloqueada na história da filosofia porque sua formulação se inicia com um problema mal colocado, qual seja, o da relação do par uno-múltiplo. Para ser mais preciso, pode-se dizer que o conceito de multiplicidade não se autonomiza enquanto as relações entre o uno e o múltiplo forem compreendidas como um misto de suas respectivas determinações, isto é, quando o múltiplo é dito expor o que o uno já contém ou quando o uno é tomado como o recolhimento do que o múltiplo dele expõe.

A tentativa de Bergson, segundo Deleuze (ibidem), teria sido a de demonstrar que as determinações recíprocas do uno e do múltiplo podem misturar indevidamente elementos que diferem em natureza, de modo que seria possivel desfazer esse misto separando os termos que nele aparecem confusos. Quando essa depuração do misto se completasse, as determinações do par uno-múltiplo poderiam ser finalmente colocadas sob os auspícios de um problema verdadeiro que explicaria a gênese do uno e do múltiplo sob o campo de forças do conceito de multiplicidade; isto é, os termos do par uno-múltiplo, ao contrário de sua vigência na história da filosofia, não seriam considerados de modo que aquele aparecesse como originário, já que princípio ontológico ou essência do ser, e este, o múltiplo, como derivativo, fenomênico, como uma dispersão empírica em que o uno se estilhaça ou se ofusca, mas para se difundir, para se manter latente, e, enfim, ser recolhido ou reencontrado nos cacos do múltiplo. Ou, em outras palavras, pode-se dizer que com o conceito de multiplicidade, o múltiplo deixa de ser o adjetivo que qualifica ou manifesta o substantivo uno, para receber, ele também, uma definição substancial.

Desde que o conceito de multiplicidade opera essa reviravolta no par uno-múltiplo, surge não mais o dualismo substantivo-adjetivo, mas uma tipologia das multiplicidades. De fato, Bergson define dois tipos de multiplicidade, a saber, "a de termos justapostos no espaço e a dos estados que se fundem na duração", ou seja, as multiplicidades numéricas ou extensas e as multiplicidades qualitativas ou de duração (p.8). Porém, precisamos perguntar a Deleuze por que esses dois tipos de multiplicidade são definidos exatamente pela determinação justaposição de termos no espaço e pela determinação fusão de estados na duração e, por que, enfim, tais determinações se confundiram constituindo um empecilho, na história da filosofia, para a emergência do conceito de multiplicidade. Por que o dualismo do unomúltiplo é uma confusão entre dois tipos de multiplicidade e por que essa confusão é posta em evidência, desde que o conceito de multiplicidade exerce sua função depuradora? 


\section{Fragilidade do misto de espaço e duração}

Ocorre que todo o misto mal analisado tem por base a confusão entre espaço e duração. O espaço apresenta apenas as diferenças de graus entre as coisas, ele segmenta a matéria segundo o aumento e diminuição de suas partes, por isso é um modo de abstrair a materialidade dos objetos segundo uma "homogeneidade quantitativa". Já a duração apresenta a "heterogeneidade qualitativa" da matéria, isto é, ela é uma "maneira de estar no tempo" que não se reduz a quantidades homogêneas, e por isso destaca a diferença de natureza entre os objetos e de um objeto consigo mesmo (p.23-24). Assim, por exemplo, sempre que o açúcar derrete na água, certamente, há uma diminuição de grau - ele se dilui - relativa à materialidade formal, porém, igualmente, sua natureza se modifica, pois o açúcar passa de sólido a líquido, ocorrendo uma alteração em sua materialidade substancial ou em sua essência, que define um estado.

Quando o múltiplo tem seu alcance formulado a partir das diferenças de grau no espaço, a duração, por seu turno, homogeneiza-se, de modo que não levamos em conta as diferenças de natureza ou alterações do estado. Tal superposição na formulação dos problemas é a origem dos mistos, e todo misto gera um dualismo como método filosófico. Tal é o caso da oposição uno-múltiplo na tradição filosófica. Neste dualismo, a essência, que é una e interior, desconhece as alterações da natureza, e torna-se tão-somente o ponto de referência do aumento/diminuição de diferenças de grau nas partes da matéria. Assim, o espaço em vez de incorporar a variabilidade da essência na duração, passa a ser um "espaço auxiliar" que representa exteriormente em suas graduações a impassividade de uma essência imóvel. Porém, em sentido contrário, no dualismo do uno-múltiplo, a duração deixa de apresentar as diferenças de natureza de uma essência, e torna-se o duplo temporal das diferenças quantitativas do espaço auxiliar, ou seja, a duração mitiga-se em "tempo homogêneo". O misto justapõe os graus dos objetos no espaço, como múltiplo, bem como alinha as distinções na duração como uno (p.29-30).

Uma outra maneira de confundir a multiplicidade de espaço com a multiplicidade de duração seria identificar esta última com uma temporalidade que não é homogênea ou linear, mas relativista, enquanto o espaço dependeria dessa relatividade do tempo. Porém, o conceito deleuzeano de multiplicidade não é também um decalque do espaço-tempo da física relativista, muito embora o conceito de multiplicidade aí formulado também sirva como ponto de partida para Deleuze.

\section{Crítica da noção de multiplicidade segundo um espaço-tempo relativista}

O método filosófico dualista, portanto, é originado por um problema mal colocado, qual seja, o das relações entre espaço e duração, bem como é representado 
pelo misto em que uno e múltiplo aparecem em um par de opostos. Por isso, segundo Deleuze, o termo multiplicidade não faz parte do vocabulário da filosofia. Foi preciso esperar que a ciência, particularmente a teoria da relatividade, formulasse seu próprio conceito de multiplicidade para que a filosofia daí derivasse uma nova maneira de pensar e para que a multiplicidade, como conceito filosófico, fosse concebida. A partir daí, Deleuze procurará estabelecer contatos com pensadores, geralmente alheados da história da filosofia tradicional, e igualmente com problemas de outras áreas, dos quais ele procurará extrair um elemento novo para sua teoria das multiplicidades.

De fato, ao tratar de Bergson, Deleuze (1966) observa como esse filósofo já teria proposto um remanejamento na maneira pela qual o físico e matemático Riemann concebia a multiplicidade. Deleuze esclarece que, justamente nesse interesse de Bergson pela ciência, a noção de multiplicidade começa a ser dotada de alcance filosófico, e observa que uma das principais conseqüências dessa iniciativa seria que a teoria das multiplicidades alcança uma autonomia tal que já se tornava apta a fornecer uma crítica sobre a formulação riemanniana que, aliás, seria em parte adotada por Einstein quando da elaboração de sua Teoria da Relatividade. Vejamos como isso se dá.

Para Riemann, as coisas poderiam ser classificadas em dois tipos de multiplicidades, a saber, as que são determinadas em razão de suas dimensões e as que são determinadas em razão de variáveis independentes. A primeira delas é a "multiplicidade discreta", caracterizada pela definição de um princípio métrico entre as partes que a compõem; o segundo tipo de multiplicidade é denominado "multiplicidade contínua", pois ela encontra o seu princípio métrico não nas partes de seus elementos, mas em outra coisa, como em fenômenos ou em forças que agem nessas multiplicidades e dependem, portanto, não do espaço, mas do tempo, ou melhor, elas definiriam o espaçotempo da relatividade. Assim, por um lado, as multiplicidades discretas são as que podem ser expressas em termos numéricos, dada sua caracterização quantitativa; por outro, as multiplicidades contínuas são não numéricas ou indivisíveis, visto que seu princípio métrico depende de qualidades ou estados variáveis de seus elementos (p.31-3).

É justamente quanto à caracterização das multiplicidades contínuas que, segundo Deleuze, Bergson pretendia aprofundar a própria teoria riemanniana das multiplicidades, pois esta última visava a reformular, ou precisar, a concepção científica de espaço, mas ao fazê-lo consegue apenas definir as multiplicidades discretas do ponto de vista negativo, isto é, como uma noção de espaço, que envolve um princípio ligado a estados temporais. Para Bergson, esta operação teria incorrido no equívoco de reeditar mais uma vez o misto espaço-duração, ao passo que, se o elemento próprio da multiplicidade fosse a duração, estaria preservada a distinção real entre esse tipo de multiplicidade e a multiplicidade discreta ou espacial, bem como a própria definição de multiplicidade se revestiria de um caráter positivo.

Trocando os termos em miúdo, isto quer dizer que, quando um elemento de uma multiplicidade de duração (contínua) se divide, a multiplicidade muda de natureza, e não apenas de referência a um estado temporal como princípio métrico. Contudo, mesmo Bergson não leva a cabo esta crítica. Será Deleuze quem o fará ao 
restabelecer uma aliança da ciência física com a filosofia bergsoniana a fim de ativar sua própria teoria das multiplicidades. Mas, como a crítica do conceito de multiplicidade no âmbito da física seria transferida ao campo da filosofia, sem que esta última fosse obrigada a se submeter a padrões epistemológicos que lhe ditassem, do exterior, a tarefa de criar conceitos?

A crítica de Deleuze a Bergson e a Riemann incide sobre o fato de que a sua formulação do conceito de multiplicidade parece se restringir, em graus diferentes, como observamos, a uma tipologia das multiplicidades, não ficando definido claramente o envolvimento que há entre os dois tipos de multiplicidade. Esta crítica incidiria, igualmente, sobre outros momentos em que uma tipologia das multiplicidades faz as vezes de conceito, como, por exemplo, no dualismo entre as multiplicidades definidas por Husserl, entre as "multiplicidades de grandeza ou extensivas" e as "multiplicidades de distância" de Meinong e Russel, e entre as "multiplicidades de massa" e as "multiplicidades de matilha" de Canetti (Deleuze \& Guattari, 1980, p.45-6; Deleuze, 1986, p.23, 124 nota 46; 1990, p.130). De fato, Deleuze deseja elevar o alcance dessa tipologia a uma ontologia das multiplicidades, a fim de que os tipos ou regimes de multiplicidade não corram o risco de se submeter a um princípio ontológico que não esteja de acordo com a sua caracterização e que, por isso, ponha por terra a distinção do conceito de multiplicidade.

\section{Crítica da definição do ser em termos de uno-múltiplo}

Ora, Bergson teria logrado transformar a tipologia riemanniana da multiplicidade - discreta e contínua - em uma verdeira noção de multiplicidade. Porém, de acordo com Deleuze, a própria tentativa bergsoniana teria abortado, pois ele não conseguira dar à ela um alcance ontológico, de modo a esclarecer de que maneira se daria a relação entre multiplicidade de duração e multiplicidade espacial, pois o dualismo ontológico do uno e do múltiplo agora poderia retornar establecendo-se entre os dois tipos de multiplicidade e obliterando distinção que o conceito desejava conferir-lhe (1986, p.22). Porém vejamos, antes de mais nada, como a definição do alcance ontológico da teoria deleuzeana das multiplicidades toma impulso a partir do interior da filosofia bergsoniana, pois em Bergson estão presentes todos os elementos para que esse intento seja logrado.

Para Deleuze, o conceito de multiplicidade é importante, antes de mais nada, porque ele evita o pensamento abstrato, no que ele procura combinar dualmente uno e múltiplo. Por exemplo, não seria suficiente integrar ambos os termos ontologicamente, afirmando que o uno já é múltiplo, que o uno passa no interior do múltiplo, pois o uno assim concebido é geral demais. Esta concepção das relações entre o uno e o múltiplo seria insuficiente para compor um conceito de multiplicidade porque de nada valeria a oposição de um conceito geral do uno a um conceito geral de múltiplo, se tal oposição resultasse somente em uma unidade do múltiplo igualmente abstrata, isto é, uma unidade ontológica que se desviara na fulguração do empírico para reco- 
brar-se, para achar-se de novo por entre os caminhos do múltiplo. Igualar o múltiplo ao empírico, estando ele percorrido intrinsecamente pelo uno, é uma maneira de rebaixá-lo do ponto de vista ontológico.

O que garantiria, então, que o movimento do real, isto é, neste caso, do múltiplo por meio do uno, não fosse falseado por uma abstração? Deleuze responde peremptoriamente a esta indagação: "não se reunirá jamais o concreto combinando-se a insuficiência de um conceito com a insuficiência de seu oposto; não se reunirá o singular corrigindo uma generalidade por outra generalidade" (1966, p.38).

O grande equívoco deste "movimento do conceito abstrato" é observar a produção do real em um devir muito geral, no qual se perdem os seus matizes; matizes que são por demais sutis e ariscos para as malhas da abstração. Então, Deleuze nos convida a uma nova definição de devir, uma definição que o tome como movimento do real e simultaneamente como movimento do ser. Não se deve, por um lado, compreender o ser como uma origem (uno em geral) a partir da qual se instauraria o não-ser como uma série de gradações até seu retorno ao estado original; caso em que o devir e o múltiplo são concebidos como um "intervalo" em que todas as coisas estão compreendidas. Não se deve, por outro lado, opor ser e não-ser como se fossem forças (múltiplo em geral) que, ao se combinarem, produziriam todas as coisas; caso em que o devir e o múltiplo teriam uma função genética, mas essa produção das coisas dependeria de oposições radicadas no real. Em ambos os casos, uno e múltiplo combinar-se-iam abstrata ou genericamente, porque o movimento do real e do devir estaria de alguma maneira, fosse por degradação fosse por oposição, marcado por uma negatividade em relação ao ser. É que o negativo, que justamente combina ser e devir como degradação e oposição, como analisa Deleuze, impede que o ser seja visto em suas "diferenças de natureza" e que o devir seja as variações dessas diferenças no ser (p.41-2).

Resumidas as críticas de Deleuze acerca do emprego do conceito de multiplicidade na ciência e na filosofia, expliquemos melhor o alcance ontológico que este deve encerrar.

\section{Alcance ontológico do conceito de multiplicidade}

\section{"Multiplicidade virtual" e "multiplicidade atual"}

De acordo com Deleuze, pensar a multiplicidade da duração é uma das progressões da filosofia bergsoniana. A outra progressão seria redefinir a noção científica de espaço, procurando dar-lhe um caráter ontológico. A teoria deleuzeana das multiplicidades, por sua vez, afina-se ao observar a novidade que o conceito filosófico de multiplicidade traria para a ciência. Essa tentativa de caracterizar o espaço como multiplicidade emergirá novamente em vários pontos de seus trabalhos posteriores, mas aparece enunciado basicamente na definição de uma "geome- 
tria operatória ou projetiva" cujo objeto seria um "espaço liso" ou "espaço qualquer" (Deleuze \& Guattari, 1980, p.258, 451-2, 484-5, 605, 610-1; Deleuze, 1985, p.13, 16-7, $26,167-9 ; 1993$, p.176-7). Basta, para os objetivos do presenteartigo, que indiquemos amaneira deleuzeana de integrar o espaço e a duração por intermédio de um princípio ontológico afeito à teoria das multiplicidades.

Antes de mais nada, é necessário resguardar-se de conceber o espaço apenas como uma desnaturação a que estaria sujeita a pureza da duração, pois é possível tratá-lo como uma relação entre as coisas e entre as durações (Deleuze, 1966, p.25, 44). Abordar a ontologia sob o ponto de vista das diferenças de grau no espaço seria perpetrar uma ilusão que contamina não somente a filosofia, como também a ciência; mas, em contrapartida, observar o espaço participando do ser como subproduto de uma atividade essencial, seria duplicar essa ilusão. Deleuze nos convida a compreender o espaço e todas as atualizações da duração como participantes das virtualidades do ser em suas diferenças de natureza. Evita-se, assim, que a multiplicidade espacial de Bergson recaia em um dualismo em relação à multiplicidade de duração.

Para tanto, Deleuze começa por criar uma terminologia própria. Denomina multiplicidade virtual aquela marcada pelo tempo universal ou duração, e multiplicidade atual aquela marcada por uma pluralidade de tempos, cada um correspondendo a uma linha de atualização, e cada tempo atual é um grau coexistente na unidade da duração, sendo o espaço, justamente, o elemento que acolhe as variações da duração (p.103-5). Sendo assim, os dois tipos de multiplicidade, dada a relação entre eles, definem um sistema-multiplicidade.

Nesse livro (1966) dedicado a Bergson, então, observamos como o conceito de multiplicidade está ligado ao problema da duração, pois é ele que permite não só definir os dois tipos de multiplicidade, como também a relação sistêmica entre eles. Porém, Deleuze ainda daria um passo adiante na definição do conceito de multiplicidade ao procurar esclarecer em minúcia a relação desse conceito com um problema, dando a este também um envolvimento direto com conceito de multiplicidade, uma vez que na filosofia de Bergson ele figurava apenas como diretor de um método filosófico para desfazer os mistos de espaço e duração e, daí, propiciar a formulação do conceito. Por isso, Diferença e repetição e Lógica do sentido são livros-chave na teoria deleuzeana das multiplicidades. Neles, vemos a noção de problema adquirir um alcance ontológico ao mesmo tempo em que o conceito de multiplicidade ganha uma definição isenta de dualismos.

\section{Noção de problema e conceito de multiplicidade}

O alcance da relação entre o conceito de multiplicidade e o problema pode ser já apreendido no nível mais geral de sua caracterização terminológica, pois se a multiplicidade é um sistema de diferenças (virtual e atual), o problema equivale ao conjunto de um sistema de diferenças/singularidades (1968, p.161-2). Como elementos, pode-se afirmar que as diferenças convivem na multiplicidade, mas o problema é o que faz as 
diferenças coexistirem. Não basta que as diferenças/singularidades apareçam juntas, é necessário ainda que o único elo de ligação entre elas seja a própria diferença. 0 elo entre as diferenças é, por conseguinte, um problema.

Nesta perspectiva é que Deleuze irá definir sua posição em face da filosofia do cálculo. De fato, ele transforma o cálculo diferencial em elemento dinâmico de sua filosofia. Isto porque, para ele, o cálculo diferencial deve deixar de ser a expressão matemática das soluções para se tornar o elemento do problema por excelência (p.235).

Como já observáramos, a atribuição de verdade e falsidade não começa com os casos de solução, mas com a posição do próprio problema. Tal afirmação possui dois sentidos importantes. Em primeiro lugar, cada problema tem a solução que merece de acordo com o caráter de sua posição. Em segundo, e a seu turno, as condições de posição de um problema não desaparecem com a sua solução. Ambas as conseqüências daquela afirmação procuram indicar, então, que os problemas nunca são dados, são sim "objetidades ideais", o que lhes confere um alcance transcendental; isto é, trata-se de um ato do pensamento pelo qual, nas palavras de Deleuze, "o problema ou o sentido, é ao mesmo tempo o lugar de uma verdade originária e a gênese de uma verdade derivada" (p.207). Convém, portanto, indagar a Deleuze: de que maneira convivem a origem e a derivação da verdade no problema?

\section{Problema: universalidade abstrata $\mathrm{x}$ singularidade concreta}

Tal convivência é possível desde que o condicionamento de um problema não lhe seja exterior. O rompimento dessa cláusula de condicionamento intrínseco ocorre, em primeiro lugar, quando imaginamos que os casos de solução de um problema são dados nas proposições, de maneira que se retroage das proposições para perguntas que lhes correspondem. Assim, haveria tantos problemas quantos seriam as proposições enunciáveis. Essa exterioridade no condicionamento do problema Deleuze denomina "ilusão lógica". Não obstante, essa ilusão lógica ainda é duplicada por uma "ilusão filosófica". Esta última perfaz uma exterioridade de condicionamento segundo a qual a forma dos problemas depende da forma da possibilidade das proposições, isto é, os problemas devem ser formulados de acordo com a sua resolubilidade variável, dependente de um determinado elemento que pode ter uma feição intrínseca, porém define um universal, seja ele a opinião do senso comum ou uma opinião científica baseada no cálculo matemático de probabilidades (1968, p.207-10; 1969, p.147). Em nenhum desses casos, com efeito, o problema define um sentido intrínseco que esteja de acordo com a "produção do verdadeiro no pensamento", pois ambas as ilusões caracterizam a recognição da verdade, isto é, uma realimentação entre a solução como possível e o problema como dado.

Deleuze, justamente, procura reverter essas duas espécies de ilusão indicando que, ao se decalcar os problemas dos casos de solução, o máximo que lhe pode ser conferido é uma generalidade abstrata correspondente à reunião das respostas 
particulares de cada proposição. Assim, por exemplo, Kant, se por um lado, concebe a Idéia como problemática, por outro, descaracteriza o seu alcance ao submeter a série das hipotéticas (proposições particulares) à série das categóricas (proposições gerais). A fim de dirimir essa superposição entre problema e solução, os problemas devem ser entendidos eles próprios como "idéias", dando às soluções universalidade (1968, p.210-11). Mas essa universalidade do problema, como não é abstrato, é formado por relações que, determinando as condições do problema, transformam-no em uma singularidade concreta. O universal e o singular encontram-se como um problema que determina uma multiplicidade, de maneira que os casos de solução passam a ser avaliados pela repartição das condições do problema, e não pelo dualismo do falso/verdadeiro, valor de verdade que transfere ao problema a extensão das soluções (hipotético ou categórico), e não uma intensidade que lhe seria intrínseca.

Graças a essa caracterização das multiplicidades problemáticas, Deleuze pode afirmar que "elas não são essências simples, mas complexas, multiplicidades de relações e singularidades correspondentes" (p.212, grifo nosso). Reponhamos, portanto, tendo em vista os esclarecimentos precedentes sobre a noção de problema, a caracterização do conceito de multiplicidade, observando por via de que procedimentos o encontro entre o singular e o universal define uma tipologia das multiplicidades que está isenta do dualismo em que incorreram as tentativas de filósofos e cientistas em definir o conceito de multiplicidade, como assinalamos acima.

\section{Problema: componentes do conceito de multiplicidade}

A distribuição das singularidades ou diferenças que determinam as condições de um problema não são ainda a solução, mas a gênese dela. Por isso, é necessário distinguir, para o conceito de multiplicidade, três componentes: "ligações ideais" como condições do problema ou multiplicidade virtual, como determinação dessas condições, e "relações atuais" ou multiplicidadade atual, como casos de solução (1969, p.144-5). O conceito deleuzeano de multiplicidade somente se estabeleceria, definitivamente, quando as multiplicidades virtual e atual fossem imanentes uma à outra, sendo o princípio dessa imanência uma multiplicidade substantiva. A noção de problema é de importância fundamantal para esse acabamento do conceito. O importante é, de que forma, no conceito de multiplicidade, esses componentes aparecem juntos.

Um problema é simultaneamente transcendente e imanente em relação aos casos de sua solução: Transcendente, porque, antes de mais nada, corresponde a um "sistema de ligações ideais", que define a "instância transcendente". Imanente, porque essas ligações especificam-se em relações atuais, definindo o "campo de resolubilidade científica". Porém, não existe nenhuma semelhança entre esses dois componentes, de maneira que a instância transcendente pudesse decalcar suas ligações das relações do campo de resolubilidade, pois o terceiro componente (distribuição de singularidades), que define o "campo simbólico" ou "problemático", vem estabelecer 
a coexistência entre transcendência e imanência do problema com relação às suas soluções. Com efeito, a distribuição das singularidades no campo simbólico determina as condições (ligações ideais) da instância transcendente, ao mesmo tempo que é a gênese das relações atuais que definem o simbolismo. Sendo assim, quais as conseqüências da convivência desses três fatores do problema como componentes do conceito de multiplicidade?

Problema e solução são unívocos, sem que por isso sejam idênticos, semelhantes ou análogos e, justamente graças a esse caráter, a sua convivência corresponde a um conceito de multiplicidade em que não há oposição nem contradição entre o uno e o múltiplo ou entre os dois tipos de multiplicidades (virtual e atual).

Um problema, como alerta Deleuze, não desaparece com as soluções. Pelo contrário, os problemas "persistem", eles "insistem" nelas (1968, p.212). Nesse momento, a teoria das multiplicidades volta-se para a tarefa de lembrar que toda a solução que parece ter apaziguado ou elidido o problema que a gerou é uma solução inadequada, mas, em contrapartida, não é também uma solução falsa, pois a redistribuição dos pontos singulares de uma multiplicidade pode não apenas oferecer uma solução adequada, como também reativar um problema que nunca deixa de insistir. Recolocar o problema significa livrar-se das ilusões do pensamento e, portanto, como nos diz.Deleuze, "reverter as relações ou as repartições supostas do empírico e do transcendental" (p.216).

Tal reversão é tarefa do conceito de multiplicidade, a começar pelo par unomúltiplo. A definição de novas relações entre o empírico e o transcendental, entre o atual e o virtual é essencial para a filosofia de Deleuze, pois ela preenche uma questão que caracteriza sua originalidade, a saber, com que finalidade um ser uno sairia de si mesmo para diferenciar-se como ser-múltiplo, se ele vai deparar-se com o que ele já era? Essa finalidade somente pode ser exterior a seu princípio ontológico ou ela erige em princípio ontológico alguma coisa que está programada para aparecer em sua exteriorização, para que o ser, enfim, se reencontre. Ao contrário, um ser da multiplicidade interiorizou a diferença, a diferença está no ser, de modo que, no momento em que ele se exterioriza, deseja apenas reproduzir a diferenciação que já produz como princípio ontológico. O ser da multiplicidade, de fato, tem um motivo para sair de si mesmo; é que não precisa comprovar sua unidade original, pois a unidade da diferença no ser já implica que ele não pode permanecer num estado de recolhimento. 
CARDOSO JÚNIOR, H. R. The origin of the concept of multiplicity in Gilles Deleuze's. Trans/Form/Ação (São Paulo), v.19, p.151-161, 1996.

- ABSTRACT: Deleuze seeks for his own concept of multiplicity through the issue of multiplicity both in Riemann's physical theory and in Bergson's philosophy. This attempt states for Deleuze's peculiar creation of concepts. In fact, he draws out from riemannian and bergsonian concepts of multiplicity new features for the notions of space and time. Hence, he is able to supply his own concept with an ontological spread.

- KEYWORDS: Multiplicity; Deleuze; Bergson; Riemann.

\section{Referências bibliográficas}

DELEUZE, G. Le bergsonisme. Paris: PUF, 1966.

Différence et répétition. Paris: PUF, 1968.

Logique du sens. Paris: Minuit, 1969.

Cinéma 2: L'image-temps. Paris: Minuit, 1985.

Foucault. Paris: Minuit, 1986.

Pourparlers. Paris: Minuit, 1990.

Critique et clinique. Paris: Minuit, 1993.

DELEUZE, G., GUATTARI, F. Mille plateaux. Paris: Minuit, 1980. 